\title{
Numerical Simulation and Experimental Research on Forward Extrusion of Planet Gear
}

\author{
XIA Yu-feng ${ }^{1, a}$, Wang $L i^{1, b}$ Ren $L i^{1, c}$, YE Cai-hong ${ }^{1, d}$ \\ College of Materials Science and Engineering, Chongqing University \\ Chongqing, China \\ awilly@cqu.edu.cn, bwow3wangli@163.com, ${ }^{c}$ Renli1991@cqu.edu.cn, d20130902005@cqu.edu.cn
}

Keywords: Planet gear; Forward extrusion; Orthogonal experiment; Numerical simulation.

\begin{abstract}
In this work, a forward extrusion technology was developed for spur gear, which used in truck wheel redactor. In order to achieve better technological parameters combination, the finite element method (FEM) and orthogonal experiment were utilized to research the process of planet gear forward extrusion. Forging load, heights of sunk angle, maximum damage factor and wear of mould were chosen as evaluating indicators. Die-entrance angle, die working length, blank diameter coefficient, forming speed and friction coefficient were taken into consideration to analysis the influence on forming quality for the spur gear. The significant factors and the optimal value, i.e. die-entrance angle $\left(30^{\circ}\right)$, the blank diameter coefficient $(1.20)$ and the forming speed $(70 \mathrm{~mm} / \mathrm{s})$ were determined by using comprehensive balance method. After the technological experiment, the qualified quality planet gear can be manufactured by the optimized forward extrusion.
\end{abstract}

\section{INTRODUCTION}

Planet spur gear is a frequently used part in automotive reducer mechanism. Generally, the forming technologies for planetary gear are machining and precision forging. Compared to the mechanical processing, the precision forging has obvious advantages in efficiency, productivity, cost saving, and mechanical properties [1]. And benefit from the good surface quality and high dimensional accuracy, the cold forging process has attracted more and more attention in gear production. Cold forging processes for gear include closed die forging and forward extrusion process. In closed die forging, the metallic materials flow along the radial direction to fill the cavity of mould by the pressure of the punch. In this case, with the increasing of the contact area between blank and mould cavity, the forming force rises sharply. However, in forward extrusion, the forming load reaches a certain value during the initial deformation stage, and it can maintain a relatively stable development trend in a whole process. Therefore, forward extrusion can reduce forming force and die wear more effectively compared to the closed die forging in planet gear production [2, 3].

In this paper, a planet gear applied in truck wheel reducer was formed via cold forward extrusion. In order to reduce the collapse angle and other defects during one-time forward extrusion [4], orthogonal experimental design and FEM were adopted to analyze the forming process. Maximum forging load, heights of gear sunk angle, forging damage and die wear values were treated as evaluation indicators; and die-entrance angle, die working length, blank diameter coefficient, forming speed and friction coefficient act as process parameters. The purpose of this work is to get a reasonable combination of these process parameters to improve the quality of the planet spur gear, and make technological test verification. 


\section{Planetary SPUR GeAR FORWARD EXTRUSION FORMING PROCESS}

\section{Process analysis of planetary spur gear}

The part drawing for planetary spur gear was shown in Fig.1. The material was 20CrMo, and the parameters for the gear were as follows: number of teeth was $16(z=16)$, gear modulus was $4(m=4)$, and pressure angle was 20 degree $\left(\alpha=20^{\circ}\right)$. The forward extrusion process was displayed in Fig.2. The final product demands smooth surface for tooth surface, and cracks, scratches and other defects are not allowed. The blank should be extruded a blind hole before forward extrusion, which the inner bore and the outer diameter had a high concentricity to ensure concentricity of final gear product.

\section{Selection of orthogonal experiment parameters}

The most influential factors during cold forward extrusion processes were die-entrance angle, die working length, blank diameter coefficient, forming speed and friction coefficient [5]. Table 1 shows the range of various factors. The blank diameter can be expressed as Equation(1).

$$
d=m \cdot k
$$

Where $\mathrm{d}$ is blank diameter, $\mathrm{k}$ is blank diameter coefficient blank diameter coefficient, $\mathrm{m}$ is gear modulus, $\mathrm{z}$ is the number of teeth.
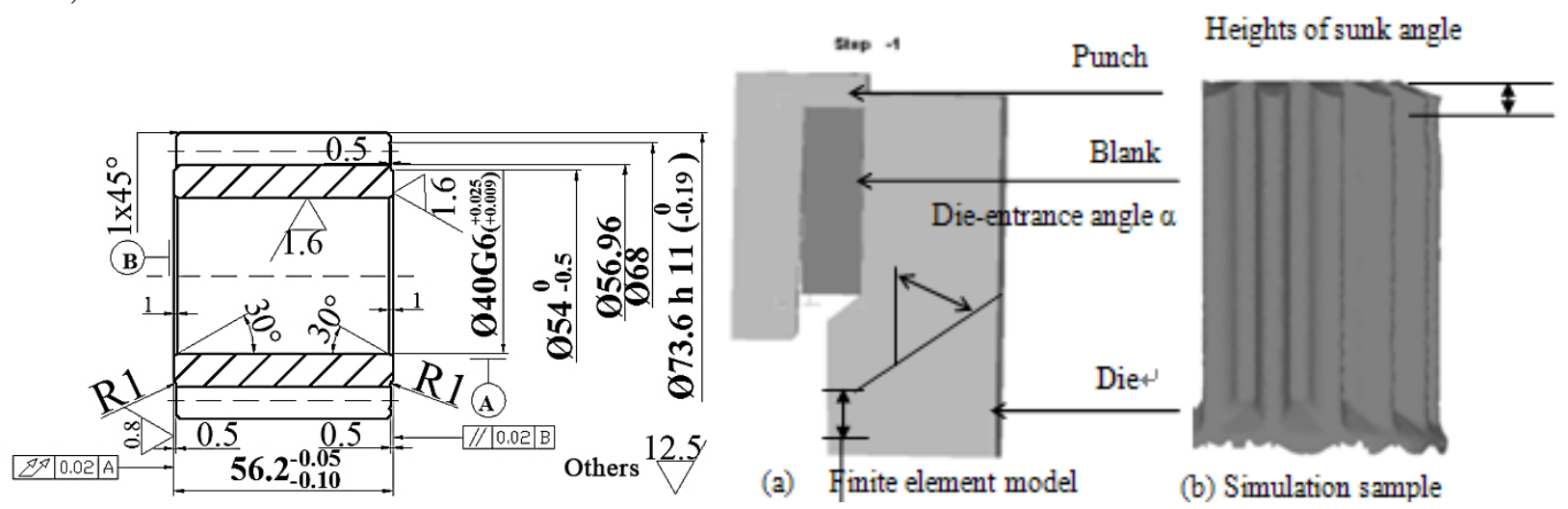

Fig.1 Detail drawing of spur gear

Fig.3 FEM model for Spur gear forward extrusion

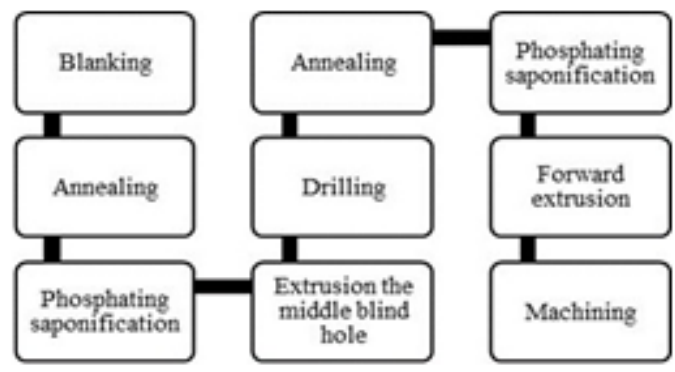

Fig.2 The forward extrusion 
TABLE 1 The value range of parameters

\begin{tabular}{|c|c|c|c|c|c|}
\hline \multirow{2}{*}{ Level } & \multicolumn{5}{|c|}{ Different Parameters } \\
\cline { 2 - 6 } & $A /{ }^{\circ}$ & $B / m m$ & $C / m m$ & $D /(m m / s)$ & 10 \\
\hline Level 1 & 35 & 4 & 1.17 & 30 & 0.06 \\
\hline Level 2 & 40 & 6 & 1.18 & 50 & 0.08 \\
\hline Level 3 & 45 & 8 & 1.19 & 70 & 0.12 \\
\hline Level 4 & 50 & 10 & 1.20 & 0.10 \\
\hline
\end{tabular}

In order to facilitate representation, $\mathrm{A}, \mathrm{B}, \mathrm{C}, \mathrm{D}$ and $\mathrm{E}$ were chosen to substitute the die-entrance angle, die working length, blank diameter coefficient, forming speed and friction coefficient successively; $\mathrm{X}_{1}$, $\mathrm{X}_{2}, \mathrm{X}_{3}, \mathrm{X}_{4}$ each indicated forging load, height of sunk angle, maximum damage factor and wear of mould.

\section{Establishment of the FEM mold}

Due to the symmetrical structure of the planet gear, the symmetry plane was set to save computing time. So in this FEM mold, there was only one complete gear tooth for numerical simulation. The blank was a hollow rod (plastic deformation body), which included 40,000 meshing number, and the local refinement was carried at the large deformation area for the blank. Punch and die were rigid bodies, which included 50,000 meshing number, and the local refinement was utilized to the tooth section and guidance tape. The specific material of blank was AISI-4120 (20CrMo), the yield strength reached 930MPa. The initial temperature for forming was $20^{\circ} \mathrm{C}$, the friction model was shear friction model. Mould material was AISI-D2 (Cold), and the wear degree can be analyzed using Archard mold of wear calculation. The FEM mold for the planet spur was shown in Fig.3.

\section{EXPERIMENTAL DESIGN AND ANALYSIS}

\section{Orthogonal experiment}

Orthogonal design is a very extensive approach to solve a multi-objective problem. Using the Standardization orthogonal table, multi-factor and multi-level orthogonal test can be arranged correctly. Furthermore, the multi-objective optimization problem can be solved by analyzing the orthogonal test results. In this work, the five-factor and four-level orthogonal table was designed to study the forward extrusion process. The orthogonal test and FEM result were shown in TABLE 2.

TABLE 2 The table of orthogonal test and FEM result

\begin{tabular}{|c|c|c|c|c|c|c|c|c|c|}
\hline \multirow{2}{*}{$\begin{array}{c}\text { Test } \\
\text { number }\end{array}$} & \multicolumn{9}{|c|}{ Parameters and FEM Result } \\
\cline { 2 - 10 } & $A /{ }^{\circ}$ & $B / m m$ & $C / m m$ & $D /(\mathrm{mm} / \mathrm{s})$ & $E$ & $X_{1} / t$ & $X_{2} / \mathrm{mm}$ & $X_{3}$ & $X_{4} / \times 10^{-2} \mu m$ \\
\hline 1 & 35 & 4 & 1.17 & 10 & 0.06 & 16.4 & 1.53 & 0.71 & 9.02 \\
\hline 2 & 35 & 6 & 1.18 & 30 & 0.08 & 16.6 & 1.41 & 0.577 & 9.58 \\
\hline 3 & 35 & 8 & 1.19 & 50 & 0.1 & 17.9 & 1.24 & 0.62 & 9.08 \\
\hline 4 & 35 & 10 & 1.20 & 70 & 0.12 & 21.9 & 0.88 & 0.725 & 9.45 \\
\hline 5 & 40 & 4 & 1.18 & 50 & 0.12 & 19.5 & 1.61 & 0.583 & 9.86 \\
\hline 6 & 40 & 6 & 1.17 & 70 & 0.1 & 18.7 & 1.10 & 0.69 & 9.49 \\
\hline 7 & 40 & 8 & 1.2 & 10 & 0.08 & 21.0 & 0.90 & 0.657 & 10.6 \\
\hline 8 & 40 & 10 & 1.19 & 30 & 0.06 & 19.6 & 1.18 & 0.72 & 10.7 \\
\hline 9 & 45 & 4 & 1.19 & 70 & 0.08 & 20.0 & 1.43 & 0.628 & 9.56 \\
\hline 10 & 45 & 6 & 1.2 & 50 & 0.06 & 22.5 & 2.01 & 0.712 & 9.74 \\
\hline
\end{tabular}




\begin{tabular}{|c|c|c|c|c|c|c|c|c|c|}
\hline 11 & 45 & 8 & 1.17 & 30 & 0.12 & 19.4 & 1.93 & 0.839 & 10.3 \\
\hline 12 & 45 & 10 & 1.18 & 10 & 0.1 & 19.5 & 2.31 & 0.69 & 11.0 \\
\hline 13 & 50 & 4 & 1.2 & 30 & 0.1 & 22.9 & 1.15 & 0.788 & 8.89 \\
\hline 14 & 50 & 6 & 1.19 & 10 & 0.12 & 22.7 & 1.74 & 0.652 & 9.16 \\
\hline 15 & 50 & 8 & 1.18 & 70 & 0.06 & 19.7 & 1.18 & 0.52 & 8.50 \\
\hline 16 & 50 & 10 & 1.17 & 50 & 0.08 & 18.0 & 1.20 & 0.66 & 8.21 \\
\hline
\end{tabular}

TABLE 3 The range analysis result of orthogonal test data

\begin{tabular}{|c|c|c|c|c|c|c|}
\hline $\begin{array}{l}\text { Evaluate } \\
\text { indicators }\end{array}$ & index & $A$ & $B$ & C & $D$ & $E$ \\
\hline \multirow{5}{*}{ Forging load } & $K 1$ & 18.200 & 19.700 & 18.125 & 19.875 & 19.550 \\
\hline & $K 2$ & 19.700 & 20.125 & 18.800 & 19.625 & 18.900 \\
\hline & K3 & 20.325 & 19.500 & 20.050 & 19.475 & 19.725 \\
\hline & K4 & 20.825 & 19.725 & 22.075 & 20.075 & 20.875 \\
\hline & $R$ & 2.625 & 0.625 & 3.950 & 0.600 & 1.975 \\
\hline \multirow{5}{*}{$\begin{array}{l}\text { Heights of } \\
\text { sunk angle }\end{array}$} & $K 1$ & 0.655 & 0.675 & 0.725 & 0.675 & 0.658 \\
\hline & $K 2$ & 0.660 & 0.660 & 0.593 & 0.726 & 0.631 \\
\hline & K3 & 0.717 & 0.659 & 0.650 & 0.644 & 0.700 \\
\hline & K4 & 0.655 & 0.694 & 0.721 & 0.643 & 0.700 \\
\hline & $R$ & 0.062 & 0.035 & 0.132 & 0.083 & 0.069 \\
\hline \multirow{5}{*}{$\begin{array}{c}\text { Maximum } \\
\text { damage factor }\end{array}$} & $K 1$ & 1.265 & 1.430 & 1.440 & 1.620 & 1.472 \\
\hline & $K 2$ & 1.198 & 1.563 & 1.627 & 1.417 & 1.235 \\
\hline & K3 & 1.917 & 1.313 & 1.397 & 1.512 & 1.450 \\
\hline & K4 & 1.317 & 1.393 & 1.232 & 1.147 & 1.540 \\
\hline & $R$ & 0.719 & 0.250 & 0.395 & 0.473 & 0.305 \\
\hline \multirow{5}{*}{ Mould wear } & $K 1$ & 9.282 & 9.255 & 9.945 & 9.945 & 9.490 \\
\hline & $K 2$ & 10.163 & 9.492 & 9.867 & 9.867 & 9.488 \\
\hline & K3 & 10.150 & 9.620 & 9.223 & 9.223 & 9.615 \\
\hline & K4 & 8.690 & 9.840 & 9.250 & 9.250 & 9.692 \\
\hline & $R$ & 1.473 & 0.508 & 0.722 & 0.772 & 0.204 \\
\hline
\end{tabular}

The analysis of orthogonal experiment results based on comprehensive balance analyzing

Comprehensive balance analysis method is commonly used in multi-objective optimization analysis. A set of optimal parameter combinations for individual evaluation indicators were obtained first. Then, comprehensive balance analysis was built according to the importance of the indicators, and the significance degree affected by the various factors. Ultimately, the optimal combination of parameters can be acquired [6].

In this work, the effect rule for each indicator caused by various factors was researched via the range analysis method, the greater the range value $(R)$ the greater the impact degree, and the smaller the contrary. TABLE 3 on behalf of the range analysis for orthogonal experiment. As shown in Table 3, the impact degree order of those five factors to forging load was $C>A>E>B>D$, the corresponding combination of parameters was A1B3C1D3E2; the impact degree order of those five factors to maximum damage factor was $\mathrm{C}>\mathrm{D}>\mathrm{E}>\mathrm{A}>\mathrm{B}$, the corresponding combination of parameters was A1B3C2D4E2; the impact degree order of those five factors to height of sunk angle was $A>D>C>E>B$, the corresponding combination of parameters was A2B3C4D4E2; and the impact degree order of those five factors to wear of mould was $\mathrm{A}>\mathrm{D}>\mathrm{C}>\mathrm{B}>\mathrm{E}$, the corresponding combination of parameters was A4B1C3D3E2. 
Variance analysis was needed to determine the most significant factors for each index. To intuitively reflecting the impact of various factors on target variables, the F ratio was introduced. F ratio represents the ratio to the square of the average deviation caused by the changes of factors' level and the square of the evaluation deviation. According to variance analysis theory, when $\mathrm{F}$ ratio $\geq \mathrm{F} 0.01$, it is considered the factors to be examined has a high impact for the objective function, and when the $\mathrm{F}$ ratio $<\mathrm{F} 0.1$, it is indicated that influence for the objective function caused by the factors is not obviously. Based on the analysis of $\mathrm{F}$ ratio, factor A has a significant influence on forging load, height of sunk angle and mould wear; factor $\mathrm{C}$ has a great impact on forging load and maximum damage factor; factor $\mathrm{D}$ has an obviously affecting on mould wear; however, factor $\mathrm{B}$ and $\mathrm{C}$ have no significant effect on those evaluation indicators.

In order to get the optimal parameters combination, it is very necessary to make a deeper study for factor A, B and C. Firstly, factor A affects forging load, height of sunk angle and mould wear, and the influential parameters are $A_{1}, A_{2}$ and $A_{4}$. According to Table 3 , the main effects for target value are $A_{1}$ and $\mathrm{A}_{4}$, the die-entrance angle (A) is more appropriate to take $\mathrm{A}_{1}$ as the final value. Secondly, factor $\mathrm{C}$ influences forging load and maximum damage factor, and the most influential parameters are $\mathrm{C}_{3}$ and $\mathrm{C}_{4}$. Compared to $\mathrm{C}_{3}$, the maximum damage factor decreases $8.65 \%$ and the forging load only $2.40 \%$ higher when chosen $\mathrm{C}_{4}$. Therefore, the blank diameter coefficient $(\mathrm{C})$ is better to pick $\mathrm{C}_{4}$. Thirdly, factor $\mathrm{D}$ has an impact on mould wear and the major factors are $\mathrm{D}_{3}$ and $\mathrm{D}_{4}$. However, under the condition of other indicators did not change significantly, the height of sunk angle is $32.89 \%$ lower than $\mathrm{D}_{3}$ when chosen $\mathrm{D}_{4}$. Thus, the best forming speed (D) is $\mathrm{D}_{4}$. Finally, factor $\mathrm{B}$ and $\mathrm{E}$ are preferably selected according to the actual situation. For the convenience of the simulation and verification, the die working length (B) takes $\mathrm{B}_{1}$, and the friction coefficient $(\mathrm{E})$ takes $\mathrm{E}_{2}$.

\section{Simulation verification and process test}

Fig. 4 shows the simulation result obtained by the optimum parameters when using comprehensive balance analysis. According to the result, the peak forging load reaches $17.4 \mathrm{t}$, which is $4.4 \%$ lower than the average value in Table 3. The maximum damage factor is 0.608 , which is almost the same as the minimum average in Table 3 . The height of sunk angle is $0.7 \mathrm{~mm}, 39 \%$ lower than the minimum average in Table 3. The mould wear is $8.08 \times 10^{-2} \mu \mathrm{m}, 7 \%$ lower than the minimum average in Table 3 . In summary, the optimization analysis for improving gear forward extrusion is very helpful, meanwhile orthogonal experiment results proved to be correct.

To verify the optimal parameters combination in actual production, the process test was experimented at a 500T hydraulic machine. Figure 5 shows the sample for planetary spur gear using cold forward extrusion. In accordance with the sample, the gear teeth are full after forming, and the sunk angle is only about $1 \mathrm{~mm}$, which can be removed by machining. With smooth tooth surface, no cracks and other defects, the planet spur gear can be formed by the cold forward extrusion.

\section{Conclusion}

In this paper, orthogonal design and FEM were adopted to analyze the cold forward extrusion process for the planet spur gear and optimize the process parameters. The following conclusions can be summarized by the experimental verification process:

Die-entrance angle, die working length, blank diameter coefficient, forming speed and friction coefficient indeed have influence on the forward extrusion process for planet gear.

Orthogonal design and FEM show that die-entrance angle, blank diameter coefficient and forming speed are the most determined factors in gear forming process. The best parameters are acquired when the die-entrance angle is $35^{\circ}$, diameter coefficient is 1.20 and forming speed is $70 \mathrm{~mm} / \mathrm{s}$. 
Through numerical simulation and test verification, the use of the forward extrusion process can produce a good surface quality, and acquire high dimensional accuracy of planetary gear products.

\section{ACKNOWLEDGMENT}

The author acknowledges that support was received from the Fundamental Research Funds for the Central Universities (No. CDJZR13130082).

\section{REFERENCES}

[1] Jin Junsong. Research on the key technology of near-net shaped forming for gears used in car [D]. Wuhan: Huazhong University of Science and Technology, 2009:1-2..

[2] Xia Juchen. Methods of metal precision forming[M]. Beijing: National Defense Industry Press, 2007.

[3] Yu Dezhe, Wang Xinyun, Jin Junsong Li Jianjun and Xia Jushen. Numerical simulation investigation on forward extrusion process of hollow cylindrical helical gear [J]. Forging \& Stamping Technology, 2013(2):147-150.

[4] Xiong Feng, Zhang Ruhua, Sun Ling, Wang Shi and Zhu Yuefeng. Metal flow of a kind of spur gear precision forming [J]. Forging \& Stamping Technology, 2014, 39(5):144-149.

[5] Wang Yang. Numerical analysis and optimization of spur gear extrusion forming process [D]. Shandong: Shandong University, 2014:9-12.

[6] Zheng Youxiang. Multi-objective optimization of process parameters of aluminium alloy rib-web forgings based on orthogonal experiment [J]. Hot Working Technology, 2015, 44(9):168-172.

[7] Zhou Fengjia, Tang Yucheng, Zhou Xionghui. Optimization of extrusion part based on moving least squares response surface methodology [J]. Forging \& Stamping Technology, 2007, 32(5):77-81. 